\title{
A Educação a Distância como Política de Expansão e Interiorização da Educação Superior no Brasil
}

\author{
Pedro Antônio de Melo ${ }^{1}$ \\ Michelle Bianchini de $\mathrm{Melo}^{2}$ \\ Rogério da Silva Nunes ${ }^{3}$ \\ Se você acha a educação cara, \\ porque não experimenta a ignorância? \\ (Charles William Eliot \\ Presidente da Universidade de Harvard - EUA, 1869).
}

\section{Resumo}

Este ensaio tem como objetivo identificar o estado da arte da educação superior brasileira, presencial e a distância. Busca compreender o processo de expansão a partir da análise da LDB - Lei de Diretrizes e Bases da Educação Nacional, do Plano Nacional da Educação e do Plano de Desenvolvimento da Educação. Aponta também os principais agentes responsáveis pela transformação ocorrida nos últimos anos, e identifica pelo menos três pilares importantes para esta expansão: 1) a expansão das universidades federais pelo REUNI; 2) o Programa Universidade para Todos - PROUNI; e 3) a Universidade Aberta do Brasil - UAB. Destaque maior foi dado à educação a distância, tendo em vista que esta aparece como um elemento importantíssimo na interiorização e democratização do acesso à educação superior; sobretudo, quando utiliza recursos tecnológicos que permitem a socialização do saber. As conclusões mostram que a educação superior a distância vem crescendo em níveis exponenciais nos últimos anos, que é um processo irreversível e deverá contribuir com a formação profissional, permitindo um upgrade na vida social das pessoas. Além disso, os mecanismos de ação para a expansão devem contribuir para a elevação da qualidade de vida das pessoas, incrementando a competitividade em níveis nacional e internacional. A formação

\footnotetext{
${ }^{1}$ Doutor em Engenharia de Produção e Sistemas pela Universidade Federal de Santa Catarina. Diretor do Instituto de Pesquisas e Estudos em Administração Universitária - INPEAU. Endereço: Av. Rubens de Arruda Ramos, 3286, Centro, Florianópolis - SC - CEP 88015-702. E-mail: pedro.inpeau@gmail.com.

${ }^{2}$ Graduada em Pedagogia com habilitação em Orientação Educacional pela Universidade Federal de Santa Catarina (UFSC). Professora de Educação Básica e pesquisadora do Instituto de Pesquisas e Estudos em Administração Universitária (INPEAU). Endereço: Av. Rubens de Arruda Ramos, 3286, Centro, Florianópolis-SC-CEP 88015-702.E-mail: chelymelo@gmail.com.

${ }^{3}$ Doutor em Administração pela Universidade de São Paulo. Professor adjunto da Universidade Federal de Santa Catarina. Endereço: Departamento de Ciências da Administração, Campus Universitário,Trindade, Florinópolis -SC. CEP: 88040-900. E-mail: rogeriosnunes@hotmail.com. Artigo recebido em: 25/02/2009. Aceito em: 06/05/2009. Membro do Corpo Editorial Científico responsável pelo processo editorial: Martinho Isnard Ribeiro de Almeida.
} 
superior está se consolidando como um dos mais importantes instrumentos de renovação social neste terceiro milênio, e as universidades estão assumindo seu papel e se transformando em vetores para a concretização de uma mudança social sem precedentes na história recente do Brasil.

Palavras-chave: Expansão da Educação Superior. Educação a Distância - EaD. REUNI. PROUNI.

\section{Introdução}

Dentre os muitos desafios que o Brasil precisa enfrentar a educação superior ainda é um dos mais importantes. As taxas de inclusão de jovens na idade entre 18 e 24 anos, matriculados nas instituições públicas e privadas do país, ainda é uma das mais baixas de toda a América Latina, 12.1\%. Para ter uma ideia, os países sul-americanos vizinhos apresentam taxas muito mais elevadas, o Chile 20,6\%, a Venezuela $26 \%$ e a Argentina $40 \%$. Ainda que esta se configure um caso a parte, por ter adotado o sistema de ingresso irrestrito, refletindo em altos índices de repetência e evasão nos primeiros anos, mesmo assim é um destaque significativo (PNE, 2001). Com esses índices, o Brasil destaca-se, negativamente, não apenas entre os países com níveis de desenvolvimento semelhante, mas também entre aqueles economicamente inferiores.

A educação já está sacramentada em todo o mundo como uma função inconteste de Estado, como um caminho para o desenvolvimento humano e como direito inalienável das pessoas. No Brasil, ela deve perpassar os limites políticos e governamentais, para que os cidadãos possam alcançar seus objetivos pessoais e sociais.

A educação escolar, da pré-escola à Universidade, enquadra-se como sendo o principal mecanismo impulsionador do desenvolvimento social $e$ intelectual. O Relatório da UNESCO de 1998, Educação: um tesouro a descobrir, sob a tutela de Jacques Delors (1998, p. 89), é muito claro, incisivo e faz uma reflexão profunda a respeito da importância da educação para o desenvolvimento das pessoas. Na concepção desse educador "à educação cabe fornecer, de algum modo, os mapas de um mundo complexo e constantemente agitado e, ao mesmo tempo, a bússola que permite navegar através dele". 
Em qualquer parte do mundo tal afirmativa vem ressoando cada vez mais intensamente como uma máxima verdadeira; seja nos países tecnologicamente desenvolvidos, seja nos emergentes ou até mesmo nos subdesenvolvidos. Aplicar em educação tem sido o caminho que permite aos cidadãos e aos países saírem de um patamar inferior, de subserviência $e$ miséria, para outro melhor.

A educação, na visão de Delors (1998), está fundamentada nos quatro pilares do conhecimento: aprender a conhecer, aprender a fazer, aprender a viver juntos e aprender a ser. Esses pilares pressupõem o equilíbrio na formação, especialmente nos últimos anos, e têm se transformado em base para discussões em todos os níveis de aprendizagem.

Se o conhecimento se tornou base para o desenvolvimento mundial, já não se pode mais conceber que uma nação seja desenvolvida e soberana, sem que para isso esteja acompanhada de um forte sistema de educação superior. Brito Cruz (2009) alerta para o fato de que a teoria econômica moderna mostra que a capacidade de criar e trabalhar com o conhecimento pode garantir aos países desenvolvimento sustentável. Educar as pessoas visando o trabalho baseado no conhecimento é fundamental, como pode ser observado na construção do desenvolvimento econômico e social brasileiro, que se deu a partir da formação de quadros qualificados na Universidade pública.

Entende-se que em todos os países desenvolvidos, o ensino superior tem assumido um destacado papel, seja por seu impacto no desenvolvimento econômico, seja no desenvolvimento cultural da sociedade e, mais do que tudo isso, por seu papel no desenvolvimento do ser humano. A Universidade, neste caso, tem como atividade fundamental, educar, em todos os sentidos, pois a educação é a base de uma sociedade pluralista, democrática, em que a cidadania deixa de ser apenas um conceito formalizado em lei e passa a ser exercida plena e conscientemente por todos os seus membros (BRITO CRUZ, 2009).

Na era da informação e da comunicação em tempo real, é visível que os recursos materiais sejam cada vez mais sobrepujados pelo conhecimento, além disso, os desafios da sociedade globalizada impõem a lógica da competitividade como um fator determinante nas relações econômicas.

Sob essa perspectiva, o exercício profissional no enredado e complexo mundo do trabalho requer aprendizagens e conhecimentos que sejam advindos de um sistema que induza à dinâmica da conectividade. As empre- 
sas esperam por saberes multidisciplinares, que estejam intercalados $e$ fundamentados na formação oriunda da vida acadêmica, mas que possam ser adicionados às experiências vivenciadas. Esse requisito passa a ser cada vez mais valorizado no mundo dos negócios.

A educação, se observada por tal ótica, passa a ser um commodity, inerente e fundamental, para o desenvolvimento científico e tecnológico das nações e do potencial humano. O conhecimento dela proveniente deve servir de instrumento que permita às pessoas desenvolverem e exercerem integralmente suas potencialidades. Em função dessa reflexão inicial, pode-se destacar pelos menos três razões para se acreditar nesta hipótese:

a) os países que mais aplicam em educação e os que possuem maior índice de pessoas com acesso e formação superior estão entre os mais desenvolvidos do Planeta, ou, em processo de franco desenvolvimento. A Coreia do Sul, a China e a Índia, por exemplo, continuam investindo maciçamente em educação, ciência e tecnologia e se projetam fortemente no mercado internacional, com profissionais e produtos altamente competitivos, desafiando até mesmo potências como os EUA, a Alemanha e a França. Países como a Inglaterra, o Japão e o Canadá possuem, todos, mais de $70 \%$ de jovens na faixa etária entre 18 e 24 anos matriculados na educação superior, o que muito provavelmente tem lhes permitido manter uma posição de maior competitividade em níveis globais.

b) Pessoas com nível de escolaridade superior se destacam nas empresas que utilizam alta tecnologia. Quanto maior a formação, maior a possibilidade de pleitear melhores salários e de assumir os principais postos nas organizações. O step entre um grau e outro pode chegar a mais de $50 \%$, e a valorização continua crescendo.

c) O mercado de trabalho está procurando pessoas com alta escolaridade. Consolida-se a lógica empresarial de que pessoas que conseguem acumular mais conhecimentos são mais competitivas $e$ possuem maior flexibilidade e possibilidade de se desenvolver e se reenquadrar dentro das organizações. O conhecimento teórico acumulado, associado ao desempenho profissional dentro e fora das organizações, tem sido determinante na hora de subir ao topo da pirâmide. Logo, conhecimento é fundamental. Quando se trata de 
selecionar profissionais para o alto escalão, as empresas não perguntam mais qual é a graduação que o candidato possui, mas quantas línguas falam, onde cursou o MBA e quais são os cursos que está frequentando na educação continuada.

A educação firma-se, então, neste ambiente competitivo, como um desafio que deve ser seguido por executivos e governantes indistintamente, como um princípio sine qua non para a competividade organizacional e das nações. No Brasil, esse princípio durante o longo período da história republicana assumiu um grau de importância secundária e, em determinados períodos, foi até mesmo negligenciado, conforme pode ser aferido na história deste país. Mesmo que algumas tentativas tenham sido realizadas para expandir e melhorar a qualidade da educação brasileira, até o momento o sistema educacional mantém-se estruturado de forma injusta e ineficiente para atender as demandas requeridas pela sociedade e pela atual conjuntura socioeconômica.

Toma-se como exemplo, a reforma da educação, apresentada pelo Ministério da Educação e Cultura - MEC, em 2004. A proposta estabelece normas gerais para a educação no país, regulando a educação superior no sistema federal e alterando uma série de leis, inclusive, revendo ações do Plano Nacional de Educação de 2001. O anteprojeto, ainda parado no Congresso Nacional, contempla pelo menos três questões importantes: a) vincular a Universidade ao projeto de nação, como elemento estratégico na busca de um novo modelo de desenvolvimento, central para a consolidação de uma nação soberana, democrática, inclusiva; b) republicanizar a Universidade, como um espaço público e plural de produção de conhecimento e saberes $e$ de diálogo e interação com a sociedade civil; e c) constituição de um marco regulatório orientador de regras claras, precisas e permanentes que promovam a qualificação contínua do sistema federal de ensino e que impeçam a mercantilização da educação (MEC, 2009).

Passados quase cinco anos a proposta ainda está em pauta para discussão. Tanto o Congresso Nacional quanto a comunidade e as instituições representativas acadêmica não chegam a um consenso sobre a aprovação da reforma, enquanto os interesses maiores vão se perdendo nos debates vazios e interesseiros. Inúmeras emendas já foram apresentadas, até mesmo com avanços significativos em relação às discussões anteriores, mas pelo visto continuará aberta para novas inserções e protelações, indefinidamente. Fato semelhante ocorreu com a LDB que ficou oito anos sendo discutida no Con- 
gresso Nacional, e foi aprovada em toque de caixa em 1996. Enquanto as partes interessadas não se decidem, os problemas vão se avolumando e o país perde a oportunidade de fazer uma reforma que poderia mudar os atuais rumos da educação superior.

\subsection{Os Caminhos da Educação Superior}

A educação superior tem seu ápice na Europa entre os Séculos XI e XII, com a criação das universidades de Bolonha, Oxford, Paris e Salamanca, na Itália, Inglaterra, França e Espanha, respectivamente, consideradas as primeiras instituições formalmente criadas no mundo ocidental.

Charle e Verger (1996) advogam que no momento de sua criação, as universidades tinham como principal função fornecer pessoal qualificado para suprir as necessidades da Igreja, seja como mestres das escolas capitulares, pregadores ou bispos. O Papa tinha controle e poder sobre elas e havia destinado a cada uma delas uma função ideológica: o ensino deveria conter a ilustração da fé e da defesa da ortodoxia. Mesmo assim, tão grande foi o destaque assumido pelas instituições universitárias que, mesmo sob a tutela da igreja católica - que exercia controle sobre as pessoas naquele período elas estavam cada vez mais sendo requisitadas pelas cidades e pelo Estado. $\mathrm{O}$ interesse crescente devia-se ao fato de elas formarem intelectuais letrados e juristas competentes para suprir necessidades administrativas. Entretanto, a expansão da educação superior por meio da Universidade manteve-se em processo de estagnação por um longo período. Cerca de 300 anos depois de sua criação, existiam apenas 60 instituições ativas na Europa, e nem todos os países se beneficiaram do sistema, porquanto o monopólio do conhecimento estava nas mãos da Inglaterra, Portugal, França Itália e Polônia.

No Século XVI, de acordo com Schlemper Júnior (1989), a Espanha possuía oito universidades famosas em toda a Europa, enquanto que em Portugal apenas Coimbra mantinha-se solitária, mas em destaque. Foi apenas no Século XVI que a instituição universitária começou a firmar-se fora da Europa, dando origem às universidades de São Domingos (1538), a primeira instituição do novo mundo, e a do México (1551). Na América do Norte, as primeiras universidades apareceram sob a forma de colégios que atendiam os interesses locais: formar pastores e administradores para suprir as necessidades das colônias inglesas. Estavam entre os primeiros colégios, 
Harvard (1636), Williamsburg (1693) e Yale (1701) (CHARLE; VERGER, 1996).

Ao longo dos séculos seguintes, praticamente todos os países da América Latina constituíram pelo menos uma Universidade; o Brasil era um caso a parte, uma ilha perdida no oceano das resistências impostas por Portugal. De acordo com Schlemper Junior (1989), o país manteve-se privado, até o início do Século XIX, sem qualquer tipo de instituição de ensino superior. Foi apenas com a chegada da família real portuguesa, em 1808, que se estabeleceram as primeiras escolas superiores. Surgiram as Escolas de Medicina, de Engenharia e Artes Militares e as Academias Militar e da Marinha.

Oficialmente, a primeira Universidade brasileira aparece mais de 100 anos depois da criação dos primeiros cursos. A Universidade do Brasil, atual Universidade Federal do Rio de Janeiro, foi criada em 1920, a partir da aglutinação das Faculdades de Medicina, da Escola Politécnica do Rio de Janeiro e da Faculdade Livre de Direito. Teve como objetivo outorgar o título de doutor Honoris Causa ao Rei da Bélgica, e em seguida foi fechada. Outras experiências já haviam ocorrido no passado como a Universidade de Manaus, em 1909, e do Paraná, em 1912, mas não puderam se consolidar em função da lei vigente.

Com a criação da USP, em 1934, consolida-se a instituição universitária brasileira. A USP foi a primeira instituição a atender às normas estabelecidas pelo Estatuto das Universidades. Em 1935, foi criada a Universidade do Distrito Federal, que funcionou somente até 1939, sendo incorporada posteriormente à Universidade do Brasil (ROMANELLI, 1978).

Na sequência, aparecem as PUCs, e no ano de 1954, o Brasil já contava com 16 universidades. De 1955 a 1964 foram criadas mais 21 universidades, e neste período ocorre o processo de federalização do ensino superior brasileiro (CUNHA, 2007).

No final dos anos 60, o Brasil possuía 41 universidades públicas e 22 particulares. Desde a década de 70 , o sistema privado já havia assumido uma posição de destaque e absorvia cerca de $70 \%$ dos alunos de nível superior, enquanto o sistema público, incluindo universidades e estabelecimentos isolados, apenas 30\% (SCHLEMPER JÚNIOR, 1989).

Nas décadas de 60 e 70, as universidades públicas se expandiram rapidamente, não havendo nenhum outro projeto de expansão de destaque até o final dos anos 90. Contudo, neste mesmo período, e especialmente a partir da LDB de 1996, a rede privada regida por leis de mercado explodiu e con- 
tinuou se expandindo, principalmente nas áreas de maior concentração populacional das regióes Sul e Sudeste (MEC, 2009).

Em termos mundiais, a expansão continuou em ritmo acelerado, especialmente nos Estados Unidos, depois da Segunda Guerra Mundial. Frederico Mayor (1994), Diretor Geral da UNESCO, de 1987 até 1999, afirma que a segunda metade do Século XX foi marcada por uma verdadeira revolução no ensino superior que se torna cada vez mais um ensino de massa.

A Universidade, pelo seu prestígio e conforme analisa Rossato (2005), tornou-se uma instituição universal, e até o final da segunda metade do Século XX já havia sido implantada em, pelo menos, 167 países. O Século XX universalizou a Universidade, haja vista que das 626 universidades existentes em 1900, chegou-se ao final do século com quase 3.500 , e esse número continua crescendo. Na década de 50, havia no mundo 6,5 milhões de estudantes universitários, e em 1997, 88,2 milhões. Considerando os dados da UNESCO, estima-se que no ano 2000 o número dos universitários de todo o mundo aproximava-se dos cem milhões e para 2007, cerca de 140 milhões de estudantes. Só os EUA possuem 14 milhões de estudantes matriculados em suas universidades.

No Brasil, o Censo da Educação Superior (2008) revelou aspectos importantes da atual situação da Educação Superior brasileira. No que diz respeito às Instituições de Ensino Superior, o Censo indica que em 2007 havia no país 2.281 IES, e que, desse total, $89 \%$ estavam organizadas como iniciativa privada e apenas $11 \%$ na área pública, divididas entre federais (4,6\%), estaduais $(3,6 \%)$ e municipais $(2,7 \%)$. É importante salientar que nesses percentuais estão incluídas tanto as instituições que oferecem cursos de graduação presencial como a distância. Na categoria presencial, estão em funcionamento 23.488 cursos de graduação em todo o país. Destaca-se o incremento de 10.645 novas vagas nas Instituições Federais de Ensino Superior (IFES), e registra o ingresso de 151.640 novos estudantes, sendo que $12,7 \%$ dessas matrículas foram oferecidas no interior do país.

Em 2007, estavam matriculados 4.880.381alunos na Educação Superior, e o principal crescimento ocorreu nas regiões Norte $(8,4 \%)$ e Nordeste (7,2\%). Desse total, $54 \%$ dos alunos estudam em universidades, $32 \% \mathrm{em}$ faculdades e $14 \%$ em centros universitários. No mesmo período também houve um aumento no número de vagas nos cursos de Educação Tecnológica, 394.120 (INEP, 2009). 
Assim como no Brasil, a explosão das matrículas em nível mundial vem acompanhada de uma série de fatores que contribuíram para o crescimento da educação superior no período recente. Rossato (2005) destaca a chegada da classe média na Universidade; a explosão demográfica; a expansão do ensino secundário; e o ingresso da mulher na Universidade. A chegada da classe média à Universidade ocorre especialmente nos países onde o desenvolvimento econômico foi maior. A Universidade transforma-se em um meio de garantir o status quo, ou de ascender a novos papéis e funções criadas pela sociedade moderna; no que diz respeito à explosão demográfica, a America Latina e a África se sobressaem, e a luta por maior empenho dos poderes públicos para ampliar as vagas no ensino superior tem sido grande; a expansão do ensino secundário tem se revelado um agente determinante na criação de demanda potencial e real por vagas no terceiro grau.

Não se pode desconsiderar os aspectos políticos. $\mathrm{O}$ discurso político com ênfase na educação tem sido item relevante de toda e qualquer plataforma eleitoral, do candidato a Vereador ao Presidente da República. A inclusão da temática enseja interesses em todas as classes sociais. Um bom plano de trabalho político deve, obrigatoriamente contemplar ações nesta área, especialmente pela constante demanda. A diferença, hoje, é que o eleitor está se acostumando a cobrar promessas feitas em campanhas.

Os fatores também econômicos são preponderantes na questão da expansão. Aplicar recursos em educação é retorno garantido em curto e médio prazos, seja pela iniciativa privada ou pública. No que tange ao investimento público em educação em todos os níveis, o Brasil está na média entre os países que mais aplicam em educação no Mundo. No ano de 2006, os municípios, os estados e o governo federal investiram aproximadamente $4,4 \%$ do PIB, mas, na educação superior, o país tem mantido o investimento de $7 \%$ nos últimos anos (INEP, 2009). Na educação superior, o ideal seria uma aplicação em torno de $1 \%$ a $1,5 \%$.

\subsection{A Educação a Distância}

A Educação a Distância vem agregando em décadas experiências que resultaram em sucesso no mundo inteiro. A partir do uso de novas tecnologias, do aparecimento da fibra ótica, da comunicação via satélite, da Internet, dos vídeos e teleconferências houve uma explosão que gerou a expansão da aprendizagem virtual em praticamente todo o mundo desenvolvido. 
A compreensão do estado da arte dessa temática, por dirigentes e governantes brasileiros, deve influenciar no processo decisório, permitindo o incremento desta modalidade educacional a partir de bases sólidas e experiências vivenciadas por instituições e países. Nesse sentido, os estudos de Barros Nunes (2009) ajudam a conhecer um pouco da história do EaD no Mundo e no Brasil, ao traçar um panorama bastante alentador sobre a temática. Uma breve retrospectiva histórica indica que, provavelmente, a primeira notícia que se tem registrada, sobre esse sistema educacional, foi o anúncio das aulas por correspondência ministradas por Caleb Philips, em 1728, na Gazette de Boston, EUA. A Experiência foi seguida de muitas outras iniciativas, especialmente pelo impacto causado pela inovação, já naquele momento. Um salto no tempo, retomando no início do Século XX e chegando até a Segunda Guerra Mundial, nos dá conta de que muitas experiências foram adotadas, tendo como ênfase o ensino por correspondência. Entretanto, o principal impulso se deu a partir de meados dos anos 60, com a institucionalização de várias ações, tanto na educação secundária quanto superior, começando pela França e Inglaterra e se expandindo pelos demais países. Hoje, concretamente, mais de 80 países adotam a educação a distância em todos os níveis, atendendo milhões de estudantes em diversas instituições de ensino.

No Brasil, a EaD é marcada por uma trajetória de sucessos. Pouco antes de 1900, já existiam anúncios em jornais de circulação no Rio de Janeiro oferecendo cursos profissionalizantes por correspondência. A remessa de materiais didáticos era feita pelos correios. Em 1923, era fundada a Rádio Sociedade do Rio de Janeiro, e Projetos como o Mobral, vinculado ao governo federal com abrangência nacional, alcançaram sucesso absoluto, especialmente pelo uso do principal mecanismo de comunicação de massa, o rádio. A televisão para fins educacionais foi usada especialmente nas décadas de 60 e 70. Em 1994, o sistema Nacional de Radiodifusão Educativa foi entregue à iniciativa da Fundação Roquete Pinto que incrementou novas ações. Com o surgimento da TV fechada, outras emissoras se dedicaram a esse tipo de educação, destacando-se as TVs universitárias, o Canal Futura e a TV Cultura (BARROS NUNES, 2009).

A educação superior a distância vem se transformando num ícone mundial, que rompe fronteiras e facilita o acesso à formação superior a uma parcela significativa de pessoas no mundo inteiro. O nascimento da $\mathrm{EaD}$, na percepção de Ozires Silva (2007, p. 6), é um marco que não pode ser ignora- 
do e certamente traz para a humanidade uma aceleração acentuada para a construção de uma vida melhor para milhões de seres humanos, não importando onde estejam. Começa a se delinear o sonho da humanidade de maior nivelamento social, mais equilíbrio econômico, por força da capacidade imensa da educação formal de transformar. Mais do que isso, de capacitar cada habitante humano do planeta para, usando seus atributos pessoais, tornar-se um vencedor na sociedade moderna, quaisquer que sejam seus contornos físicos.

A educação superior a distância, como política de Estado, é uma modalidade educacional crescente no Brasil. Na Lei de Diretrizes e Bases da Educação Nacional está contemplada a $\mathrm{EaD}$, e são consideradas pelo menos duas questões importantes: a) o acesso da população às tecnologias emergentes que facilitam o crescimento dessa modalidade de educação; e b) a possibilidade de redução de custos e atendimento a uma parcela significativa da população normalmente desassistida, seja pela distância dos principais polos irradiadores de ensino, seja pela concorrência às poucas vagas existentes nas principais instituições de ensino públicas do país.

Como fator de expansão da educação superior no Brasil, a EaD está embutida no artigo 80 da LDB. Para tanto, o poder público incentivará o desenvolvimento e a veiculação de programas de ensino a distância, em todos os níveis e modalidades de ensino, e de educação continuada. Em seu $\S$ $1^{\circ}$ está definido que a educação a distância, com abertura e regime especiais, será oferecida por instituições credenciadas pela União; e no $§ 4^{\circ}$, a educação a distância gozará de tratamento diferenciado, que incluirá:

I - custos de transmissão reduzidos em canais comerciais com finalidades exclusivamente educativas;

II - concessão de canais com finalidades exclusivamente educativas;

III - reserva de tempo mínimo, sem ônus para o Poder Público, pelos concessionários de canais comerciais (LDB, 1996).

O PNE também trata a EaD com destacada importância. Deixa claro que num país como o Brasil com déficits educativos e desigualdades regionais tão elevados, a educação a distância é um meio auxiliar de indiscutível eficácia, pois serve aos propósitos, como um mecanismo facilitador no processo de universalização e democratização do ensino (PNE, 2001). 
Todos esses instrumentos legais, de certa forma, têm incentivado na execução de propostas governamentais ao desenvolvimento da EaD no país. Os resultados já podem ser sentidos. Os censos da educação superior dos últimos anos vêm apresentando resultados extraordinários em relação a essa modalidade de ensino. Para ter uma ideia, de 2003 a 2006, a educação a distância cresceu aproximadamente $571 \%$. Tal fato é marcante, principalmente pelo expressivo aumento do número de alunos matriculados no período: $315 \%$ (INEP, 2009).

Os últimos dados do Censo da educação superior (2008) indicam que em 2007, 97 instituições ofereceram cursos de graduação a distância. Esse número está acrescentado de 19 IES a mais em relação ao ano de 2006. O número de cursos de graduação aumentou significativamente, sendo criados 59 novos cursos em relação a 2006 , o que dá um aumento de $16,9 \%$ no período. No que se refere às vagas oferecidas em 2007 , houve um incremento de $89,4 \%$. O crescimento no número de vagas manteve a tendência desde 2003 (INEP, 2008).

Os dados da Abraed (2008) indicam que atualmente existem mais de dois milhões e meio de estudantes matriculados em curso de educação a distância no país em todas as categorias. Na educação superior foram oferecidas 813.550 vagas. Destaca-se que para os cursos de graduação se inscreveram 430.229 alunos, enquanto 212.246 se matricularam em 2006. No mesmo ano, concluíram o curso 25.804 estudantes. Nas instituições federais, o número de alunos em 2004 era de 159.366, em 2007 saltou para 727.657, um incremento de $356 \%$. No Quadro 1 a seguir pode-se verificar o número de alunos a distancia, por região, em instituições autorizadas pelo sistema de ensino a ministrar EaD no Brasil, de 2004 a 2007, em todas as instituições autorizadas.

A expansão da EaD no país só foi possível graças à implementação de ações que incentivaram o uso de tecnologias inovadoras em universidades. A aplicação de recursos vultosos pela iniciativa pública e privada nesse sistema permitiu, de acordo com Barros Nunes (2009), abrir possibilidades em promover oportunidades educacionais para grandes contingentes populacionais. Porquanto, além de promover a democratização, a EaD possui excepcionais vantagens sob o ponto de vista da eficiência e da qualidade, até mesmo quando envolve grandes contingentes de estudantes.

Isso é possível porque se vive, na atualidade, uma nova onda. Um sistema que reúne tanto a tecnologia comunicativa quanto a telemática. Esse 


\begin{tabular}{|l|c|c|}
\hline Região & Alunos em 2004 & Alunos em 2007 \\
\hline Centro-Oeste & 23.588 & 107.984 \\
\hline Nordeste & 57.982 & 80.482 \\
\hline Norte & 11.644 & 121.409 \\
\hline Sudeste & 163.887 & 367.945 \\
\hline Sul & 52.856 & 295.006 \\
\hline Total Geral & $\mathbf{3 0 9 . 9 5 7}$ & $\mathbf{9 7 2 . 8 2 6}$ \\
\hline
\end{tabular}

Quadro 1: Quantidade de alunos por região.

Fonte: Adaptado de Abraed (2008).

modelo proporciona condições para um aprendizado mais interativo, por meio de caminhos não lineares. Por este sistema, é o estudante quem determina seu ritmo, sua velocidade, seus percursos, bibliotecas, laboratórios de pesquisas e de equipamentos sofisticados, haja vista que o sistema pode ser acessado por qualquer usuário que esteja conectado a uma central distribuidora de serviços.

O crescimento da $\mathrm{EaD}$ no Brasil deve-se, dentre outros fatores, ao cumprimento do dispositivo legal do PNE, e a um fato político, o interesse do atual governo em atender às demandas reprimidas na educação superior; e parece que vem desempenhando esse papel. Entretanto, existe uma série de outros fatores que podem estar contribuindo para seu desenvolvimento. A Revista Exame (2009) traz uma reportagem provocante, e ao mesmo tempo preocupante. Assinala pelo menos três fatores responsáveis por esse crescimento: a) as dimensões do Brasil. Um país de dimensões continentais, certamente dificulta acesso às aulas presenciais àqueles que vivem em cidades mais remotas; b) o preço das anuidades escolares. Os dados da consultoria Hoper apontam que um curso de educação a distância custa em média $\mathrm{R} \$$ 168,00 por mês, enquanto um curso tradicional $\mathrm{R} \$ 457,00$; e c) a comodidade. O aluno não precisa se deslocar até a universidade e tem um horário de estudo mais flexível.

Ao analisar a situação da expansão da educação superior no país, principalmente pela ótica da educação a distância, é importante destacar a opinião de um dos mais renomados pensadores da Administração contemporânea, Peter Drucker. Já na década de 90, ele previa que os grandes campi 
universitários não passariam de relíquias nos próximos 30 anos; o ensino superior teria seus custos tão aumentados quanto a saúde, ao mesmo tempo que se tornaria tão importante quanto o atendimento médico. Argumentava que já se tornaria uma realidade dar aulas e palestras via satélite, por um custo bem menor. Para finalizar, ele previu que as instituições universitárias do jeito que se conhece, fisicamente estabelecidas, não sobreviveriam (DRUCKER, 1997). Se for considerado que no campo da Administração, o respeitado Drucker não cometeu deslizes, a situação é preocupante, pelo menos para as instituições que oferecem apenas cursos presenciais.

\title{
1.3 Políticas para a Educação Superior Brasileira
}

No Brasil, a expansão da educação brasileira está fundamentada em pelo menos três momentos importantes: a) aprovação pelo Congresso Nacional da Lei de Diretrizes e Bases da Educação Nacional (LDB), em 1996; b) o lançamento do Plano Nacional da Educação (PNE), em 2001; e c) o Plano de Desenvolvimento da Educação (PDE), em 2007.

a) Lei de Diretrizes e Bases da Educação Nacional - LDB.

A Lei de Diretrizes e Bases da Educação Nacional - LDB, Lei n 9.394, foi sancionada em 20 de dezembro de 1996. A promulgação ensejou todo tipo de manifestação e confrontou os mais ferrenhos opositores com seus defensores, que entenderam a Lei como um meio facilitador e direcionador de oportunidades no campo educacional. Dornas (1997, p. 20), por exemplo, tem o entendimento de que a nova lei:

\begin{abstract}
Valoriza a integração da escola com o mundo real e do trabalho e o aproveitamento pela escola de todo e qualquer conhecimento ou habilidade adquiridos pelo educando em sua vida. Permite, em qualquer nível de ensino, que se aproveite tudo que alguém aprendeu com êxito, cabendo à escola completá-lo e certificá-lo. Estimula a qualquer um a entrada e o retorno à escola, para aumentar, aprimorar ou reciclar seus conhecimentos, tendo como capital individual a investir o adquirido formal ou informalmente, com escolaridade ou sem ela.
\end{abstract}

A despeito das críticas contundentes, a LDB possibilitou ao Brasil saltar quantitativa e qualitativamente em todos os níveis educacionais. Na educa- 
ção superior, os indicadores estatísticos a partir da promulgação da Lei apontam para aceleração na criação de novas instituições e de matrículas, sem precedentes em toda a história do país.

No que tange à obrigatoriedade do Estado, no seu Título III que trata do direito à educação e do dever de estudar contempla em seu Artigo $4^{\circ}$, inciso I que o ensino fundamental é obrigatório e gratuito, inclusive para os que a ela não tiveram acesso na idade própria. $\mathrm{E}$, no Inciso $\mathrm{V}$, que o acesso aos níveis mais elevados do ensino, da pesquisa e da criação artística, ocorrerá segundo a capacidade de cada um.

A LDB abriu frentes novas e possibilidades até então impensadas para a educação superior. O artigo 44 inova, por exemplo, ao prever outras modalidades de cursos e programas. Estabelece em seu Inciso I, o aparecimento dos cursos sequenciais por campo de saber, de diferentes níveis de abrangência, aberto a candidatos que atendam aos requisitos estabelecidos pelas instituições de ensino.

b) Plano Nacional de Educação - PNE.

Visando pagar uma dívida secular com a sociedade brasileira, e até mesmo para diminuir a diferença aviltante entre os países emergentes e latino-americanos na área educacional, foi aprovada, no início do Século XXI, a Lei $n^{\circ}$ 10.172/2001, que cria o Plano Nacional de Educação (PNE). Seus objetivos muito bem delineados pretendem ver concretizados: a) a elevação global do nível de escolaridade da população, com a melhoria da qualidade do ensino em todos os níveis; b) a redução das desigualdades sociais e regionais no tocante ao acesso e à permanência, com sucesso na educação pública; e c) a democratização da gestão do ensino púbico, nos estabelecimentos oficiais, obedecendo aos princípios da participação dos profissionais da educação na elaboração do projeto pedagógico da escola e participação das comunidades escolar e local em conselhos escolares ou equivalentes (PNE, 2001).

O PNE prevê uma série de obrigações dos governos federal, estadual e municipal em todos os níveis educacionais. Para a educação superior, cabe destacar três, dentre seus 31 objetivos e metas: a) prover até o final da década, a oferta de educação superior para, pelo menos, $30 \%$ da faixa etária de 18 a 24 anos; b) estabelecer uma política de expansão que diminua as desigualdades de oferta entre as diferentes regiões do país; e c) estabelecer um amplo sistema de educação a distância, utilizando, inclusive, para ampliar as possibilidades de atendimento nos cursos presenciais, regulares ou de educação continuada (PNE, 2001). 
No que diz respeito ao item a, parece que a situação atual ainda não é a desejada quando considera os últimos dados computados pelo Censo da Educação Superior (INEP, 2009). Em 2007, o Brasil possuía 4.880.331 alunos matriculados em cursos de graduação presenciais, nas 2.282 instituições de ensino superior. Destes, somente $12 \%$ estão na faixa compreendida entre 18 e 24 anos, número bastante distante dos 30\% previstos no PNE, em 2001.

O sistema de educação a distância vem se firmando no país, especialmente a partir da criação da Universidade Aberta do Brasil - UAB, que vem ampliando as possibilidades de formação profissionais em praticamente todos os estados brasileiros. Para esse segmento educacional, os objetivos e metas do PNE já vêm sendo implementados desde sua aprovação. Pode-se enumerar: a) a oferta de cursos a distância, em nível superior, especialmente na formação de professores para a educação básica; e b) a ampliação, gradual na formação em nível superior para todas as áreas, incentivando a participação das universidades e das demais instituições de educação credenciadas.

c) Plano de Desenvolvimento da Educação - PDE.

O Plano de Desenvolvimento da Educação foi lançado em 2007 e tem como um de seus principais objetivos reverter o atual quadro educacional brasileiro atendendo às demandas da educação superior. Está alicerçado nos seguintes princípios complementares entre si: a) a expansão de oferta de vagas; b) a garantia de qualidade; c) promoção de inclusão social pela educação; d) a ordenação territorial, permitindo que o ensino de qualidade seja acessível às regiões mais remotas do país; e e) desenvolvimento econômico e social (PDE, 2008).

As universidades, dentro do que estabelece o PDE, possuem um papel estratégico relevante no cumprimento de seus objetivos, principalmente as instituições do setor público. Pode-se destacar a fundação de dez novas universidades: duas novas, duas por meio de desdobramento de outras universidades já existentes e seis outras que seriam transformadas a partir de escolas e faculdades, já existentes. Além disso, outros 88 campi universitários estão sendo criados em diversas regiões do país.

Como se pode observar, tanto a LDB, quanto o PNE e o PDE são agentes incontestes do desenvolvimento da educação nos últimos anos e servem de norte para todas as ações governamentais e institucionais.

Entretanto, a expansão da educação superior brasileira não é um fato isolado. Muitos fatores têm contribuído ao longo de décadas para que ela começasse a tomar forma e se projetar da maneira como se está experienciando 
agora. Pode-se destacar a melhoria da qualidade de vida, a competitividade empresarial promovida pelos avanços científicos e tecnológicos, as exigências do novo perfil profissional do mercado de trabalho, a globalização, ou ainda, fatores pessoais, políticos e culturais. Fatores estes de alto grau de importância que vêm pressionando e/ou influenciando as ações governamentais.

Atualmente, existem cinco programas instituídos pelo governo federal que são considerados os pilares para a democratização do acesso à educação superior: a) o Programa de Apoio a Planos de Reestruturação e Expansão das Universidades Federais - REUNI; b) o Programa Universidade para Todos PROUNI; c) a Universidade Aberta do Brasil - UAB; d) o FIES; e e) os Institutos Federais. Entretanto, para este estudo, foram analisados as ações e os resultados obtidos com os três primeiros.

REUNI - Programa de Apoio a Planos de Reestruturação e Expansão das Universidades Federais

O Programa de Apoio a Planos de Reestruturação e Expansão das Universidades Federais - REUNI, de acordo com dados do MEC (2009), foi instituído pelo Decreto $n^{\circ}$ 6.096, de 24 de abril de 2007, e tem como objetivo principal criar condições para a ampliação do acesso e permanência na educação superior, a partir do aproveitamento da estrutura física e de recursos humanos existentes nas universidades federais.

Em seu parágrafo $1^{\circ}$, está explícito que o Programa tem como meta global a elevação gradual da taxa de conclusão média dos cursos de graduação presenciais para $90 \%$ e da relação de alunos de graduação em cursos presenciais por professor para $18 \%$, ao final de cinco anos, a contar do início de cada plano.

O programa definiu, ainda, como um dos seus objetivos dotar as universidades federais de condições mínimas necessárias para ampliar o acesso e a permanência na educação superior. O REUNI é uma das ações integrantes ao Plano de Desenvolvimento da Educação (PDE). É possível caracterizar e qualificar as três etapas da expansão recente das universidades federais brasileiras a partir de três ciclos:

- Primeiro Ciclo: Expansão para o Interior (2003/2006): criação de dez novas universidades federais em todas as regiões; consolidação de duas universidades federais; criação e consolidação de 49 campi universitários. 
- Segundo Ciclo: Expansão com Reestruturação (2007/2012): adesão da totalidade das instituições federais de ensino superior; implantação de 95 campi universitários; quadro perceptível de ampliação do número de vagas da educação superior, especialmente no período noturno.

- Terceiro Ciclo: Expansão com ênfase nas interfaces internacionais (2008): criação de universidades federais em regiões territoriais estratégicas. Encontra-se em processo de criação e/ou implantação: a Universidade Federal da Integração Latino-Americana (UNILA), sediada em Foz do Iguaçu (PR); Universidade Federal do Oeste do Pará (UFOPA), sediada em Santarém (PA); Universidade Luso-AfroBrasileira (UNILAB) em Redenção (CE) e Universidade Federal da Fronteira Sul (UFFS), sediada em Chapecó (SC) (REUNI, 2009).

O REUNI pode ser resumido em seis desafios importantes: a) redução das taxas de evasão; b) ampliação da mobilidade estudantil; c) revisão da estrutura acadêmica; d) diversificação das modalidades de graduação; e) ampliação de políticas de inclusão e assistência estudantil; e f) articulação da graduação com a pós-graduação e da educação superior com a educação básica (REUNI, 2009).

O Ministro da Educação prevê investimentos em 2009 na ordem de um bilhão de reais. Esses recursos serão aplicados na infraestrutura das universidades, visando ampliar salas de aula, bibliotecas, restaurantes universitários e laboratórios de tal sorte que as instituições possam se adequar às novas demandas (HADDAD, 2008).

A expansão da educação superior ocorre, de certa maneira, em decorrência dos investimentos feitos pelos governos estadual, municipal $e$ federal. Estudos realizados pelo INEP, em parceria com o MEC, o Instituto de Pesquisa Econômica Aplicada - IPEA e o Fundo Nacional de Desenvolvimento da Educação - FNDE revelam a quantidade de recursos públicos investidos nos diferentes níveis da educação brasileira. Em 2006, houve o maior investimento público direto em educação, comparativamente ao PIB. Os governos investiram em valores absolutos, $\mathrm{R} \$ 101,8$ bilhões, o que representa $4,4 \%$ do PIB. O principal incremento foi verificado na educação básica. Nos demais níveis, o investimento se manteve constante entre 2000 e 2006, com pequenas variações, como no caso do ensino superior, que teve investimento direto igual a 0,7\% do PIB em 2006 (INEP, 2009). 


\section{PROUNI - Programa Universidade para Todos}

O Programa Universidade para Todos - PROUNI (2009) é um dos principais programas do governo federal no que tange à concessão de bolsas de estudo integrais e parciais a estudantes de cursos de graduação e sequenciais de formação específica. Foi institucionalizado pela Lei n 11.096, em 2005. Às instituições privadas de educação superior que aderem ao programa, é oferecido, em contrapartida, isenção de tributos.

O programa é oferecido aos estudantes egressos do ensino médio da rede pública ou da rede particular na condição de bolsistas integrais, com renda per capita familiar máxima que não ultrapasse três salários mínimos. A seleção dos candidatos ocorre a partir dos resultados obtidos no ENEM Exame Nacional do Ensino Médio, sendo observado o mérito estudantil a partir do desempenho acadêmico.

Quando o PROUNI foi lançado em 2005, de acordo com Mota (2008), muitas vozes se opuseram a ele, especialmente no que tange à qualidade acadêmica dos estudantes que seriam beneficiados. Nos anos seguintes essa dúvida cairia por terra, tendo em vista que nos resultados do ENADE de 2006, os bolsistas do PROUNI obtiveram, em média, notas superiores a dos demais estudantes.

O PROUNI já atendeu, desde sua criação até o primeiro semestre de 2008, aproximadamente 385 mil estudantes, e esse número continua crescendo. Desse total, 270 mil são bolsas integrais. Para ter uma ideia do volume de bolsas distribuídas em todas as unidades da federação, só no primeiro semestre do ano de 2008 foram beneficiados 106.134 estudantes. Desse total, 53.157 são bolsas parciais e 52.977 são integrais. O Estado de São Paulo ficou com a maior parcela, 40.201 bolsas, enquanto o Estado do Amapá, com apenas 213 bolsas, aparece em último lugar.

Os critérios e os valores das bolsas para atender candidatos no ano de 2009 são os seguintes: Bolsa integral - estudantes que possuam renda familiar, por pessoa, de até um salário mínimo e meio ( $\mathrm{R} \$ 622,50)$. Bolsa parcial de $50 \%$ - estudantes que possuam renda familiar, por pessoa, de até três salários mínimos $(\mathrm{R} \$ 1.245,00)$. Bolsa complementar de $\mathbf{2 5 \%}$ para estudantes que possuam renda familiar, por pessoa, de até três salários mínimos ( $\mathrm{R} \$ 1.245,00)$, destinadas exclusivamente a novos estudantes ingressantes (PROUNI, 2009). 
Almeida Junior (2009) é da opinião que o PROUNI é uma iniciativa louvável de inclusão no ensino superior, mas, como política isolada, não resolve. Entende que é preciso apoiar o aluno na Universidade e assegurar sua capacitação, para que ele possa concorrer a uma vaga no acirrado mercado de trabalho. Para esse autor, os mecanismos de financiamento do governo federal são desestimulantes e excludentes. É partidário de uma política de financiamento estudantil que contemple juros mais baixos, a partir de bancos como BNDES, o que facilitaria aos estudantes a escolha da instituição por sua identificação com a filosofia e a qualidade do estabelecimento.

\section{UAB - Universidade Aberta do Brasil}

A UAB ocupa um lugar de destaque especial no atual contexto da educação superior brasileira, tendo em vista que se apresenta como uma das principais ferramentas governamentais para incrementar a expansão da educação superior, tendo em vista que essa modalidade escolar facilita o acesso à interiorização e contempla a inclusão social em curto e médio prazos.

A UAB foi criada pelo Ministério da Educação em 2005 e tem como prioridade a formação de professores para a Educação Básica. Em função desse objetivo articula-se com instituições públicas de ensino superior, estados e municípios brasileiros. A UAB pretende, por meio da educação a distância, permitir o acesso à educação superior àquelas populações normalmente excluídas do processo educacional. O Sistema está amparado por cinco eixos fundamentais: a) Expansão pública da educação superior, considerando os processos de democratização e acesso; b) Aperfeiçoamento dos processos de gestão das instituições de ensino superior, possibilitando sua expansão em consonância com as propostas educacionais dos estados e municípios; c) A avaliação da educação superior a distância tendo por base os processos de flexibilização e regulação em implementação pelo MEC; d) As contribuições para a investigação em educação superior a distância no país; e e) $\mathrm{O}$ financiamento dos processos de implantação, execução e formação de recursos humanos em educação superior a distância (UAB, 2009).

A UAB é formada por instituições universitárias federais, estaduais e municipais, além dos Institutos de Educação Tecnológica - IFETs.

O sistema UAB oferece cursos cujo foco está na formação de professores e na administração pública. Visam atender aos professores da rede públi- 
ca da educação básica, objetivando melhorar suas qualificações e, consequentemente, a qualidade da educação nas regiões atendidas. Os cursos de graduação ofertados são os definidos pela LDB em níveis de bacharelado, licenciatura e tecnólogo. Contempla, ainda, os cursos sequenciais e de pós-graduações lato e stricto sensu.

O sistema UAB só é possível a partir do apoio recebido dos Polos de Apoio Presencial. Esses Polos oferecem infraestrutura física, tecnológica e pedagógica para que os alunos possam acompanhar os cursos e são mantidos pelos municípios e/ou estados. Os Polos localizam-se em microrregiões e municípios com pouca ou nenhuma oferta de educação superior (UAB, 2009).

Os Polos são importantes a medida que oferecem um mínimo de estrutura física, em que o aluno tem um referencial da instituição onde está matriculado, além de poder tirar suas principais dúvidas, interagir com tutores e professores que estão na outra ponta do processo.

O programa Universidade Aberta do Brasil - UAB, já disponibilizou milhares de vagas em cursos superiores, na modalidade $\mathrm{EaD}$, e a intenção do governo federal é clara: utilizar essa ferramenta para expandir, objetivando atingir a meta de interiorização e democratização do acesso à educação superior prevista no PNE, mas, principalmente aumentar a oferta de ensino público e gratuito no país.

O Sistema UAB, de acordo com Mota (2009), constitui-se de uma boa oportunidade para experiências de caráter andragógico, ou seja, por suas características de projeto piloto em estado de plena execução. A UAB apresenta as bases para a educação de adultos que trazem experiências prévias do mundo do trabalho e retornam aos bancos escolares a procura de uma formação inicial ou continuada.

Os dados mais recentes da educação superior a distância levantados pelo INEP apontam para números espetaculares em 2007. Num total de 97 instituições foram oferecidos 408 cursos de graduação, isso representa um incremento no número de vagas na ordem de $89,4 \%$ em relação a 2006 . As matrículas aumentaram $78,5 \%$ no mesmo período e já representam uma fatia de $7 \%$ do total de matrículas no ensino superior. Os dados apontam para um crescimento exponencial nesta categoria, 908,2\% em apenas cinco anos. O total de alunos matriculados em 2002 era de 40.714, e em 2007, esse número saltou para 369.766. Desse total, 275.567 estão vinculados às instituições provadas. Nas IFES estão matriculados apenas 25.552 estudantes (INEP, 2009). 
No gráfico a seguir pode-se observar a evolução do número de matrículas na graduação a distância por categoria administrativa, entre os anos de 2002 e 2007.

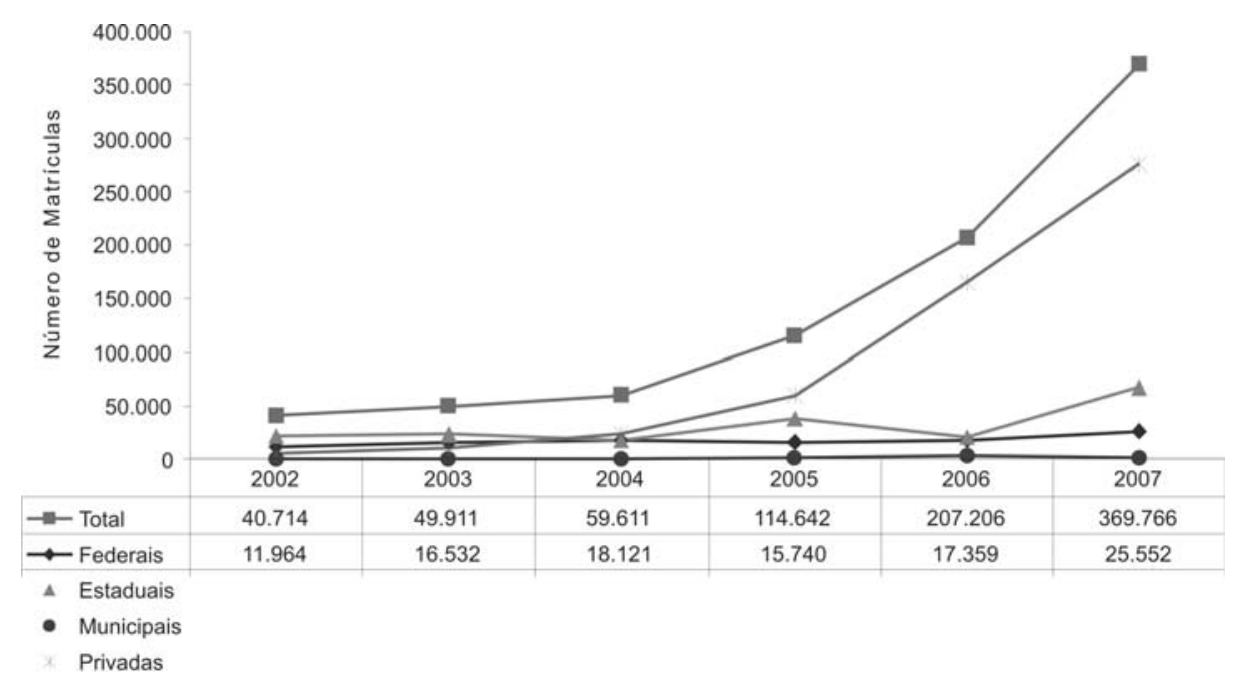

Gráfico 1: Número de matrículas na graduação a distância por categoria administrativa Fonte: INEP (2009).

\section{Considerações Finais}

A educação superior brasileira, como se pode observar nos dados apresentados neste ensaio, evidencia números e resultados bastante significativos, especialmente nos últimos anos. O estado da arte da expansão da educação superior deixa evidente que a Lei de Diretrizes e Bases da Educação Nacional, o Plano Nacional de Educação e o Plano de Desenvolvimento da Educação se transformaram nos principais vetores na consolidação do processo de expansão da educação superior brasileira.

Os dados permitem observar que a estrutura montada pelo governo para atender à demanda reprimida nesta modalidade educacional está, de certa maneira, logrando sucesso a partir da conjugação de esforços empreendidos pelos Programas UAB, PROUNI e REUNI.

Com o advento das tecnologias de informação e de comunicação, $e$ com a pressão da sociedade pela expansão de vagas, a educação superior a distância afirma-se como uma alternativa capaz de mudar os rumos da educação convencional. Mesmo assim, ainda é um paradigma que precisa ser 
negociado e assimilado tanto por professores quanto pelos estudantes que, por inúmeras razões, resistem ao velho paradigma. Todavia, percebe-se que os avanços tecnológicos e as facilidades trazidas pela Internet nos últimos anos a colocam em uma situação tão privilegiada, que se torna difícil acreditar que seja possível reverter a situação criada, ou até mesmo de manter o atual status educacional somente com a educação presencial.

As políticas públicas de expansão da educação superior a distância na última década possuem muitas variáveis e vertentes, especialmente quando se considera que elas estão baseadas na transposição de um sistema elitista para outro que permite a massificação do acesso. Os investimentos governamentais na criação de novas universidades, novos campi e o incremento da educação a distância são demonstrações inequívocas que há um processo de expansão sendo pensado e colocado em prática. O Programa de Apoio a Planos de Reestruturação e Expansão das UniversidadeS - REUNI, que figura como a primeira etapa em processo de consolidação da expansão, por exemplo, prevê o investimento de mais de dois bilhões de reais entre os anos de 2008 e 2011, e promete reestruturar as universidades, aumentar o número de cursos e criar pelo menos mais 125 mil vagas na educação superior públicas (REUNI, 2009).

Essa concentração de forças, se mantidas as atuais políticas, deverá promover a consolidação de uma das metas do Plano Nacional de Educação: colocar $30 \%$ dos jovens na faixa etária de 18 a 24 anos na educação superior. Se isso não for possível, pelo menos irá ajudar a melhorar o atual índice de $12 \%$ na categoria.

Contudo, independentemente dos números e do sucesso até aqui alcançados, fica claro que o governo e a sociedade brasileira ainda terão que enfrentar desafios mais pesados pela frente. Fica evidente, neste estudo, que para cobrir as demandas exigidas pela sociedade na educação superior, é preciso ir muito além do que já vem sendo feito, principalmente no que tange à aplicação de recursos nesta modalidade de ensino.

Democratizar o acesso à educação superior deve ser muito mais do que objetivos de governos e de pessoas, precisa ser uma política de Estado que envolva toda a Nação. Esse é um pré-requisito que precisa ser perseguido veementemente e em curto espaço de tempo. Entretanto, não se pode perder de vista a ideia de que ela precisa vir acompanhada de outro requisito fundamental, a qualidade. Fora isso, o país corre o risco de promover uma formação de massa apenas para levantar índices e de contribuir para a criação 
de uma geração inteira de universitários incompetentes, analfabetos funcionais, incapazes de se defrontar com a realidade de um mundo cada vez mais globalizado e competitivo.

Isto posto, entende-se que, independentemente dos caminhos escolhidos para serem trilhados pelo governo e pela sociedade na busca pela expansão da educação superior, a educação superior para todos precisa se tornar uma realidade, tendo em vista que continua sendo um dos principais caminhos para a realização profissional e a libertação do homem na sociedade moderna.

\title{
Distance Learning as Expasion and Interiorization Policy for Superior Education in Brazil
}

\begin{abstract}
This essay aims to identify the state of the art of Brazilian higher education, presence and distance. Seeking to understand the process of expansion from the analysis of LDB - Law of Directives and Bases of National Education, the National Plan of Education and the Education Development Plan. Points also the main agents responsible for the transformation occurred in recent years, and identifies at least three important pillars for this expansion: 1) the expansion of federal universities, by REUNI, 2) the University for All Program - PROUNI and 3) the Brazil Open University - UAB. Greater emphasis was given to distance education, since this appears as an important element in the internalization and democratization of access to higher education, especially when using technology resources that enable the socialization of knowledge. The findings show that distance education is growing at exponential levels in recent years, which is an irreversible process, and should help with training, allowing an upgrade in the social life of people. Furthermore, mechanisms of action for the expansion should contribute to raising the quality of life of people, increasing competitiveness in national and international levels. The training is consolidating as one of the most important instruments of social renewal in the third millennium, and universities are taking their role and turning into vectors for the delivery of social change unprecedented in recent history of Brazil.
\end{abstract}

Key-words: Expansion of Higher Education. Distance Education. REUNI. PROUNI. 


\section{Referências}

ABRAEAD. Anuário brasileiro estatístico de educação aberta e a Distância. 4. ed. São Paulo: Instituto Monitor, 2008.

ALMEIDA JR., Mário Veiga de. Novos desafios do ensino superior no Brasil. Disponível em: <http://www.portalbibliotecario.com.br >. Acesso em: 10 abr. 2009.

BARROS NUNES. Ivônio. A História do EaD no mundo. In: LITTO, Fredric Michael; FORMIGA, Manuel Marcos Maciel (Orgs.). Educação a distância: o estado da arte. São Paulo: Pearson Education do Brasil, 2009.

BRITO CRUZ, Carlos Henrique. A Expansão do ensino superior. Disponível em: <http://www.comciencia.br/reportagens/universidades/uni12.shtml > . Acesso em: 3 mar. 2009.

CHARLE, Christophe, VERGER, Jacques. História das universidades. São Paulo: Editora da Universidade Estadual Paulista, 1996.

CUNHA, Luiz Antônio. A Universidade crítica: o ensino superior na República Populista. São Paulo: Unesp, 2007.

DORNAS, Roberto. Diretrizes e bases da educação nacional: comentários e anotações. Belo Horizonte: Modelo Editorial, 1997.

DÉLORS, Jacques. Educação: um tesouro a descobrir. Relatório para a UNESCO da Comissão Internacional sobre a Educação para o Século XXI. São Paulo: Cortez, 1998.

DRUCKER, Peter F. Uma Bússola para tempos incertos. Revista Exame. São Paulo, v. 30, n. 7, p. 66-70. 26 mar. 1997.

LDB. Lei de Diretrizes e Bases da Educação Nacional. Lei no 9.394, de 20 de dezembro de 1996. Brasília: Disponível em: <www.planalto.gov.br>. Acesso em: 7 mar. 2009.

HADDAD, Fernando. Universidades federais vão dobrar número de vagas até 2009. Entrevista ao programa Bom Dia Ministro. Secretaria de Imprensa da Presidência da República, no dia 18/09/2008. Disponível em: $<$ http://www.agecom.ufsc.br/index.php?secao=arq\&id=7617>. Acesso em: 10 abr. 2009. 
INEP. Instituto Nacional de Estudos e Pesquisas Educacionais Anísio Teixeira. Censo da educação superior. Disponível em: < http://www.inep.gov.br/ superior/censosuperior/>. Acesso em: 5 abr. 2009.

LITTO, Frederic Michael; FORMIGA, Manuel Marcos Maciel (Orgs.). Educação a distância: o estado da arte. São Paulo: Pearson Education do Brasil, 2009.

MEC. Ministério da Educação. Resolução CES no 1 , de 27 de janeiro de 1999. Disponível em: <http://portal.mec.gov.br/cne/arquivos/pdf/ CES0199.pdf>. Acesso em: 6 abr. 2009.

Educação superior. Disponível em: < http://portal.mec.gov.br/ index.php>. Acesso em: 6 abr. 2009.

MAYOR, Frederico. La mémoire de l'avenir. Paris: Unesco, 1994.

MOTA, Ronaldo. A Universidade aberta do Brasil. In: MELO, Maria Tais de (Org.). EAD: educação sem distância. São Paulo: Laborciência, 2007.

MOTA, Ronaldo. ProUni: porta aberta para a inclusão social. In: SNACHEZ, Fábio (Coord.). Anuário Estatístico de Educação Superior aberta e a Distância. São Paulo: 2008.

OCDE. Nouvelles fomes d'enseignement supérieur. Paris: OCDE, 1991.

OZIRES Silva. A Educação sem distância. In: MELO, Maria Tais de (Org.) EAD: educação sem distância. São Paulo: Laborciência, 2007.

PDE. Plano de Desenvolvimento da Educação. MEC. Brasília, 2008.

PNE. Plano Nacional de Educação. Lei no 10.172, de 9 de janeiro de 2001. Brasília: Congresso Nacional, 2001.

PROUNI. Programa Universidade para todos. O Programa. Disponível em: $<$ http://prouni-inscricao.mec.gov.br/PROUNI/Oprograma.shtm>. Acesso em: 7 abr. 2009.

REVISTA EXAME. Os alunos estão cada vez mais longe. Caderno Gestão: educação. Edição 938, ano 43, n. 4., 11 jan. 2009. 
REUNI. Reestruturação e Expansão das Universidades Federais. O que é REUNI: apresentação. Disponível em: <http://reuni.mec.gov.br/ index.php?option $=$ com_content\&task $=$ view\&id $=15 \&$ Itemid $=2>$. Acesso em: 11 mar. 2009.

ROMANELli, Otaiza de Oliveira. História da educação no Brasil. 9. ed. Petrópolis: Vozes, 1978.

ROSSATO, Ricardo. Universidade: nove séculos de história. 2. ed. Passo Fundo: UPF, 2005.

SCHLEMPER JUNIOR, Bruno Rodolfo. Universidade e sociedade. In: VAHL, Teodoro Rogério; MEYER JR., Victor; FINGER, Almeri Paulo (Orgs.). Desafios da administração universitária. Florianópolis: UFSC, 1989. p. 70-77.

UAB. Universidade Aberta do Brasil. Instituições UAB. Disponível em: $<$ http://www.uab.capes.gov.br/ index.php?option $=$ com_content $\&$ view $=$ article $\&$ id $=104 \&$ Itemid $=30>$. Acesso em: 8 abr. 2009.

UNESCO. Relatório da comissão internacional sobre a educação para o século XXI. São Paulo: Cortez, 1998. 